\title{
Digital Art, Culture and Heritage: New constructs and consciousness
}

\author{
Jonathan P. Bowen \\ London South Bank University \\ School of Engineering \\ London SE1 OAA, UK \\ http://www.jpbowen.com \\ jonathan.bowen@/sbu.ac.uk
}

\author{
Tula Giannini \\ Pratt Institute \\ School of Information \\ New York, NY 10011, USA \\ http://sites.google.com/view/tgiannini/ \\ giannini@pratt.edu
}

Rachel Ara

Thames-Side Studios

Harrington Way, Woolwich

London SE18 5NR, UK

http://www.2ra.co

rachel@fluxit.co.uk
Andy Lomas

Goldsmiths, University of London

Department of Computing

London SE14 6NW, UK

http://www.andylomas.com

andylomas@gmail.com
Judith Siefring

Bodleian Libraries

University of Oxford

Oxford OX1 3BG

UK

judith.siefring@bodleian.ox.ac.uk

\begin{abstract}
This half-day Symposium explores themes of digital art, culture, and heritage, bringing together speakers from a range of disciplines to consider technology with respect to artistic and academic practice. As we increasingly see ourselves and life through a digital lens and the world communicated on digital screens, we experience altered states of being and consciousness in ways that blur the lines between digital and physical reality, while our ways of thinking and seeing become a digital stream of consciousness that flows between place and cyberspace. We have entered the postdigital world and are living, working, and thinking with machines as our computational culture driven by artificial intelligence and machine learning embeds itself in everyday life and threads across art, culture, and heritage, juxtaposing them in the digital profusion of human creativity on the Internet.
\end{abstract}

Computational culture. Al art. Digital aesthetics. Digital art. Digital culture. Digital heritage. Digitalism. Postdigital.

\section{INTRODUCTION}

This half day-long Symposium of invited talks on the first day of the EVA London 2019 Conference follows on from the previous three EVA London Symposiums held since 2016 (Bowen \& Giannini 2016; Bowen, Giannini \& Polmeer 2017; Bowen, Giannini, et al. 2018). The Symposium initially started in association with the Pratt Institute London Summer School, with an emphasis on digital culture (Bowen \& Giannini 2014). A collaboration with the Royal College of Art developed, providing an artistic and philosophical angle to the Symposium (Polmeer 2016). Aspects of digital culture (Giannini \& Bowen 2018) continue in this year's Symposium, which considers issues for digital artists and curators.
The 2019 Symposium covers considerations of digital culture, from both a historical and contemporary context. The presenters and chairs come from a variety of backgrounds, including both artists and academics. All the speakers have also contributed to a recent book on Museums and Digital Culture (Ara 2019; Lomas 2019; Siefring 2019 ), edited by the chairs of the Symposium (Giannini \& Bowen 2019a).

\section{DIGITAL CULTURE IN THE AGE OF AI}

Experiencing the impact of artificial intelligence (AI) and its expanding presence in cultural zones of human activity, the rapid emergence of Al presents us with compelling reasons to reassess what it means to be human or to be an artist, and to ask whether those qualities remain valued by society - 
for example, intellect and knowing, creativity, imagination, and intuition - or will these too be assumed by $\mathrm{Al}$ and computing. One impact, which might be a new stage in human evolution, is in learning and education, as academics scramble to identify what students need to know to be able to thrive in the age of Al (Han 2019). Some students are increasingly uncertain about the value of education and question its focus on computing and $\mathrm{Al}$, wondering in what fields they can pursue lasting opportunities.

At the same time, computing is being overwhelmed by $\mathrm{Al}$ so that computers and machines are teaching themselves, developing and improving while big data and analytics are replacing human decisionmaking: we ask Google to answer our questions, and Alexa to do daily tasks while programs are designed for users with no musical training to instantly compose, as we compete with avatars that look and sound like the pop stars we applaud while computers are learning to code themselves in ways that model the human coding process (Galeon 2017). And we look forward to the results of the British Library project, Living with Machines collaborating with the Alan Turing Institute designed to "revolutionise research" (British Library 2018).

These developments might seem to sit in opposition to the current wave of enthusiasm and euphoria we observe in a new generation high on $\mathrm{Al}$ and data which is transporting us beyond our physical self into a digital realm, a universe of expanding views and new possibilities causing us to seek new constructs of our digital self and attain deeper states of consciousness.

This seeming digital dichotomy or dilemma calls for new constructs of human values and existence. As we broaden our perspectives of art and humanities from the Greeks and Romans to the Renaissance and Enlightenment, the familiar pillars of culture are being redefined in light of global Internet access to diverse cultures and collections, and with access to developments in digital technologies for digital arts and humanities, students are discovering new ways to be creative using digital tools, such as VR and AR for user experience - for example, on view at the Fashion Institute of Technology (FIT) on $7^{\text {th }}$ Avenue in New York City is the exhibition, The Future is Immersive (see Figure 1). FIT artists and technicians using the Google Tilt Brush VR headset created artwork based on paintings of the Bronx by Tom Christopher for patients at the Montefiore Medical Center to experience "during treatment and beyond." Visitors to the gallery of FIT's Pomerantz Center are able to use the VR headsets transporting them "to a brave new world of artistic virtual reality." (FIT Newsroom 2019)
From the moment Shannon and Turing gave us digital computing (Giannini \& Bowen 2017), Al and machine learning, showing us both the theory and applications, there has been no looking back to what we now see as an unstoppable force that is transforming human behaviour while generating new constructs of being and consciousness, that in turn is changing our sense of identity and place in the post-digital world. Our ways of thinking are now inexorably linked to computational culture, the driving power of $\mathrm{Al}$ and machine learning. Will we cede our humanness to Al, or will we define new constructs that heighten our consciousness and individual identity, finding new ways of being human in digital reality? More than ever, we find in digital art and expression, and the messages they convey, the power of art to shine light on holistic approaches that bring into harmony human and artificial intelligence. The arts and humanities have held sway in illuminating what it means to be human and to express the deeper meaning of life, although more challenged than ever before, will they continue to play their all-important role

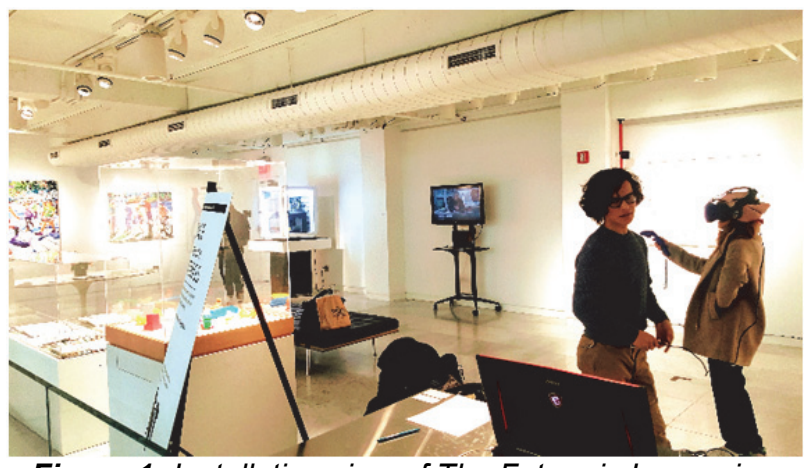

Figure 1: Installation view of The Future is Immersive, FIT Pomerantz Gallery, $7^{\text {th }}$ Ave. NYC,

Right, visitor using the Google VR headset seeing $3 D$ images of Bronx scenes based on Christopher's paintings, far left. (Photo by T. Giannini, March 28, 2019)

Derek Beres, Director of Content for RChain Cooperative, poses the question, "How will virtual reality change your mind's consciousness?" He wonders about the impact of inhabiting virtual worlds "in an environment created by another mind," and referring to Marshall McLuhan's book Understanding Media where he quotes the poet, W. B. Yeats, "You are who you are because of your environment. What happens in a virtual world in an environment created by another mind?" Although the book was published in 1964, these ideas seem fresh, as we experience the prevalence of $\mathrm{Al}$ and virtual reality in our mind's eye (Beres 2018).

\section{Computational Culture - Al and Art}

In autumn 2018, the art world was stunned when an Al generated so-called "painting" sold at Christie's for US\$432,500 - which begs the question - can Al create art? (Christie's 2018). When Giannini interviewed the artist Rachel Ara for 
the book, Museum and Digital Culture (Giannini \& Bowen 2019), the topic of art and Al arose. Ara points out that her highly acclaimed work, 'This Much I'm Worth':

\begin{abstract}
"utilizes very simple programs, in industrial terms. For anything that has a functioning algorithm, people think $\mathrm{Al}, \mathrm{Al}, \mathrm{Al}$, because it's a buzzword. So, there's a cynical take on this, that people are associating the buzzwords such as VR, AR, mixed reality Al with their work to give it currency. Therefore, the artist is creating this myth themselves about what they are using in the process. Curators might be blindly picking up on this and marketing the work as groundbreaking or a first and not questioning the quality. [...] There are also many computational people who can do complex, clever things, but for me there must be more for it to be art." (Ara \& Giannini 2019)
\end{abstract}

$\mathrm{Al}$ art has attracted much attention in academic circles and museums. From copying old art, to creating new works. For example, Ahmed Elgammal, director of the Art and Artificial Intelligence Lab at Rutgers University in New Brunswick, NJ, USA, inaugurated his art algorithm in February 2017. Drawing on some 80,000 digitised images of Western paintings and after initial tests and adjustments to his system, AICAN (Al-Creative Adversarial Networks), he produced a set of what he considered exciting images. Al researchers at the Rutgers Lab said that "they were still addressing the fundamental question of whether the images produced by their networks can be called art at all. One way to do that, surely, is to conduct a kind of visual Turing test, to show the output of the algorithms to human evaluators, flesh-and-blood discriminators, and ask if they can tell the difference" (Christie's 2018).

The lab conducted a Turing test to see how viewers compared $\mathrm{Al}$ art to art by recognised artists. Al art did relatively well and the Lab's AICAN algorithm for generating art received high marks from Artsy. Often overlooked in these comparisons, are the expectations and visual acuity of the viewers recognizing that they are accustomed to seeing digital so that the lack of screen illumination and bright colours of "real" paintings might disappoint which means that "To regain their edge and pull higher scores on Professor Elgammal's next Turing test, humans might have to start painting more like robots" (Chun 2017).

Is the human quality of creativity being ceded to $\mathrm{Al}$ along with our cherished human attributes such as consciousness, self-awareness, emotion, love, and hate? As more human activity is usurped by $\mathrm{Al}$ using robotics, data systems and analytics, computational thinking, neural networks and the operations of "smart" environments, it seems that little attention has been paid to the effect of this paradigm shift on human identity and consciousness.

The author, Aislinn Clare McDougall, in her article on Tao Lin's novel Taipei, poses the question, what is Cyber-Consciousness, which she addresses in her exploration of the "intermediation between human consciousness and digital machinery." Although McDougall's context is literary, her discussion of the question can be applied to other artistic narratives. Taking up the qualities of modernism and post-modernism, she postulates that the qualities of digitality create a $21^{\text {st }}$-century context where human consciousness and digital machinery merge "cybernetics and computational theories of the mind." Insightfully, her observations touch upon how human computer interaction makes humans more like computers.

"Like Turing and Rothblatt [Martine] propose that human consciousness can be relocated into digital machinery, N. Katherine Hayles suggests that it is "reasonable to assume that citizens in technologically developed societies [...] are literally being re-engineered through their interactions with computation devices" (Hayles 2007, p. 102). On the other hand, Hayles answers the question 'Can humans compute?' by suggesting that the digital machinery with which we interact 're-engineers' human consciousness" (McDougall 2019, p. 4).

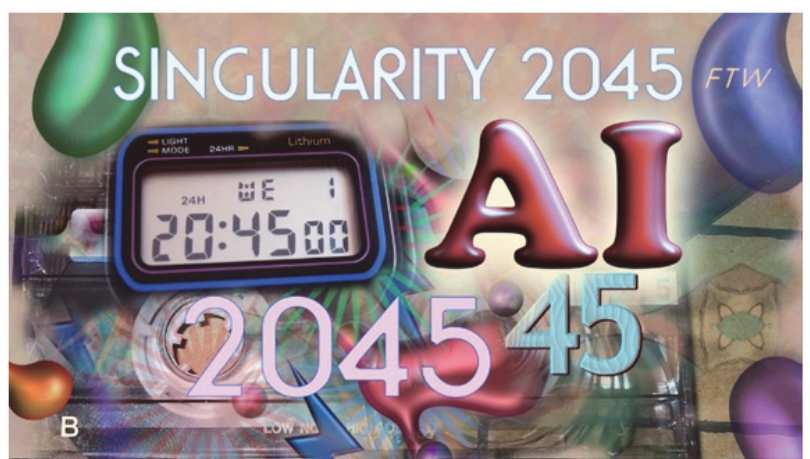

Figure 2: A representation of time ticking away to the 2045 intelligence explosion. Old technology merging into the new by Singularity Utopia, Singularity 2045 on G+. (https://plus.google.com/+Singularity-2045, 7 June 2014)

The book, The New Aesthetic and Art: Constellations of the Postdigital (Contreras-Koterby \& Mirocha 2016), looks into the future of computer art and how the control of artists over their own work is slipping away, as data takes on a life of its own reflecting the state of our postdigital world. The authors write in conclusion, "in the contemporary world technology has acquired a vitality that is selfgenerating and self-sufficient; the means that artists and programmers and others who create the methods of our interaction with data and the information produced out of that data has become so independent from the creators' full control in our post-digital world that it has asserted an autonomy 
of its own. And, therein, can be found the new aesthetic" (Contreras-Koterby \& Mirocha 2016).

Not only do they present a new aesthetic viewpoint, but they postulate as well a new form of artistic practice that would seem to disrupt centuries-old art practices that are being ceded to computational culture. As the relationship between humans and computers evolves, human creativity is being challenged by computers in the realm of art and aesthetics in ways that hark back to the Turing test. As we move full speed into digital life, are we heading for a world where human beings although not born-digital, are recreating themselves as coded objects imbued with a digital identity and living on the Internet with a URL address interacting with billions of data bits, as their coded life flows seamlessly across the digital ecosystem?

\section{PROGRAMME}

\section{Rachel Ara, Independent Artist, London}

\section{Title: What do Digital Artists do All Day?}

I present broadly my practice as an artist focusing on my more digital/computational works and the challenges particular to these pieces.

In 2017, I was appointed V\&A Artist in Residence as part of the VARI research department and tasked with responding to the V\&A's data in a meaningful manner. After months of research, this cumulated in the work 'The Transubstantiation of Knowledge' that was presented at the London Design Festival 2018. I cover the residency, thought process, and challenges behind the creation of this mixed-reality work.

In 2019, I created a new version of 'This Much I'm Worth (the self-evaluating artwork)' for the MMCA in Seoul, South Korea. This was part of a larger show called 'Vertiginous Data' featuring other artists working with data, such as Forensic Architecture, Superflex, and Zach Blas. I discuss the practical issues of building and handling largescale works that I mostly fabricate myself. I also look at how these projects manage to get made on little funding and the logistical issues behind moving and installing such works. This piece will be networked and exchange data with the European version of itself, which will be installed in Vienna as part of a show on Al at the Vienna Biennial 2019.

I also discuss how I handle fault tolerance, hardware/software issues, and maintaining multiple exhibiting works at the same time.

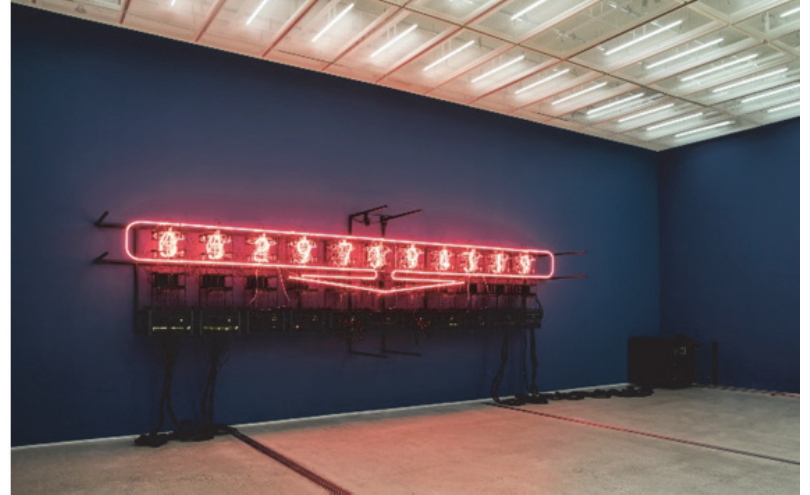

Figure 3: Installation view of the Korean Version of 'This Much I'm Worth' by Rachel Ara commissioned for the MMCA Seoul show 'Vertiginous Data' in 2019. (Photograph @ MMCA Seoul)

\section{Biography}

Rachel Ara is a conceptual and data artist who explores the relationships between gender, technology and systems of power. She graduated with a Fine Art degree from Goldsmiths College, London, where she won the prestigious Burston award. As a multi-disciplinary artist, she has a diverse skillset acquired from working 25 years in the tech industry to being a trained cabinet maker and combines them to make unique and often surprising installations and sculptures. The works are nonconformist with a socio-political edge that often incorporates humour and irony with feminist and queer concerns.

In 2016, Ara won the Aesthetica Art Prize 2016 for This Much I'm Worth, the self-evaluating artwork. Pulling on her experiences as a computer system designer, the digital sculpture draws on data and complex algorithms to calculate its own value in real time. In 2018, she was featured on the cover of the FT Wealth magazine for her monumental version of the sculpture 'This Much I'm Worth' that she engineered and built incorporating over 80 pieces of neon and a homemade animation system made from recycled materials.

In 2018, Ara was made VARI Digital Artist in Residence at the V\&A Museum in London and also showed new works at the Whitechapel Gallery ('This Much I'm Worth (Monumental Version)'), Barbican Centre ('American Beauty, a Trump L'Oeil'), Humber Street Gallery ('The Ancestors') and the V\&A ('Transubstantiation of Knowledge'). In 2019 she is showing work in two prestigious new media exhibitions at the MCCA in Seoul and the Vienna Biennial. Ara currently lives and works in London. She has previously presented at the EVA London Conference (Ara 2017). 


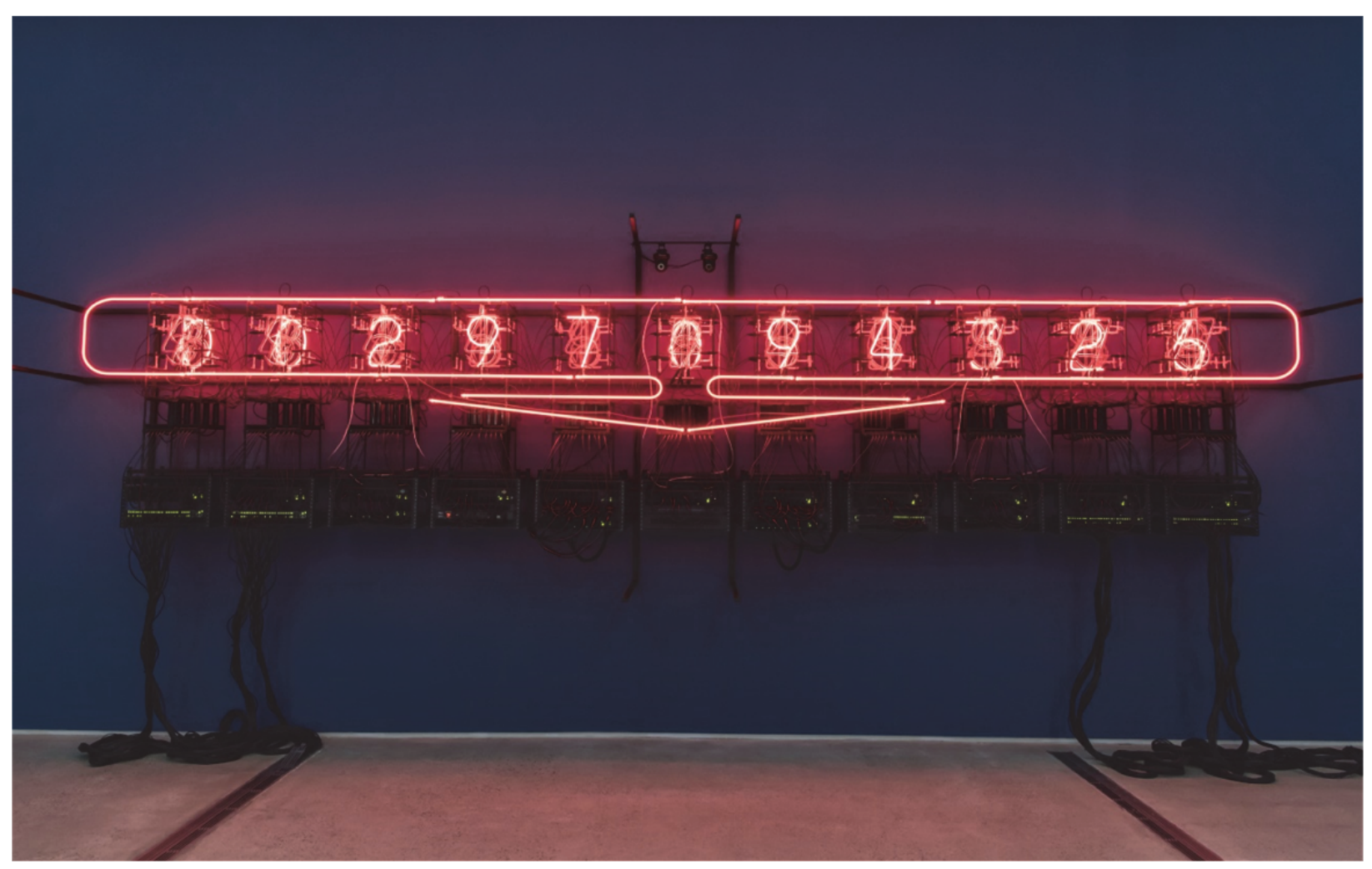

Figure 4: Front view of 'This Much I'm Worth (The self-evaluating artwork) - Korean Version' shown for the first time at the MMCA in Seoul, 2019 by the artist Rachel Ara. (Photograph @ MMCA Seoul)

Andy Lomas, Goldsmiths, University of London

\section{Title: Morphogenesis - Working with unruly system}

How are we to work creatively with generative systems that computationally create results? In particular, how should we work with systems deliberately designed to encourage emergence: genuinely unexpectedly rich behaviour that cannot be simply predicted from the constituent parts?

We need to discover the potentialities of the system we are working with, as well as the limits of its capabilities. Which features can be independently influenced, and which are co-dependent? Whether art, design or architecture, working in this manner involves changing our relationship with the computer. Traditional top-down design methods are no longer appropriate. We need to be open to a process of exploration. Participating in a search for rich interesting behaviour: selecting and influencing rather than dictating results.

A related problem is how to work with systems with large numbers of parameters. With a small number, such as three or four parameters, the space of results can be relatively easily explored by simply varying individual parameter values and plotting the effects of different combinations. This method of parameter exploration can be effective and was used by the author for earlier work such as for my 'Aggregation' (Lomas 2005) and 'Flow' (Lomas $2007)$ series. However, as the number of parameters increase, the number of samples needed to explore different sets of combinations using this type of method increases rapidly.

This problem is commonly called the 'Curse of Dimensionality' (Bellman 1961; Donoho 2000), where the number of samples that need to be taken increases exponentially with the number of parameters. With complex systems capable of richly emergent behaviour these problems are further compounded: a direct consequence of complexity is that parameters that drive the system often work in difficult to comprehend, unintuitive ways. Effects are typically non-linear, often with sudden tipping points as the system goes from one type of behaviour to another. In particular, in many systems the most interesting emergent behaviour occurs close to the boundary of regularity and chaos (Kauffman 1996).

This raises the idea of working with the machine not merely as a medium for artwork but as an active collaborator in the process of exploration and discovery. Can computational methods be used to allow exploration of generative systems in ways that would not be otherwise possible? The computer becomes an active part of the process of discovery, not just as the medium used to create artefacts (Lomas 2018). 
Digital Art, Culture and Heritage: New constructs and consciousness Jonathan P. Bowen, Tula Giannini, Rachel Ara, Andy Lomas \& Judith Siefring

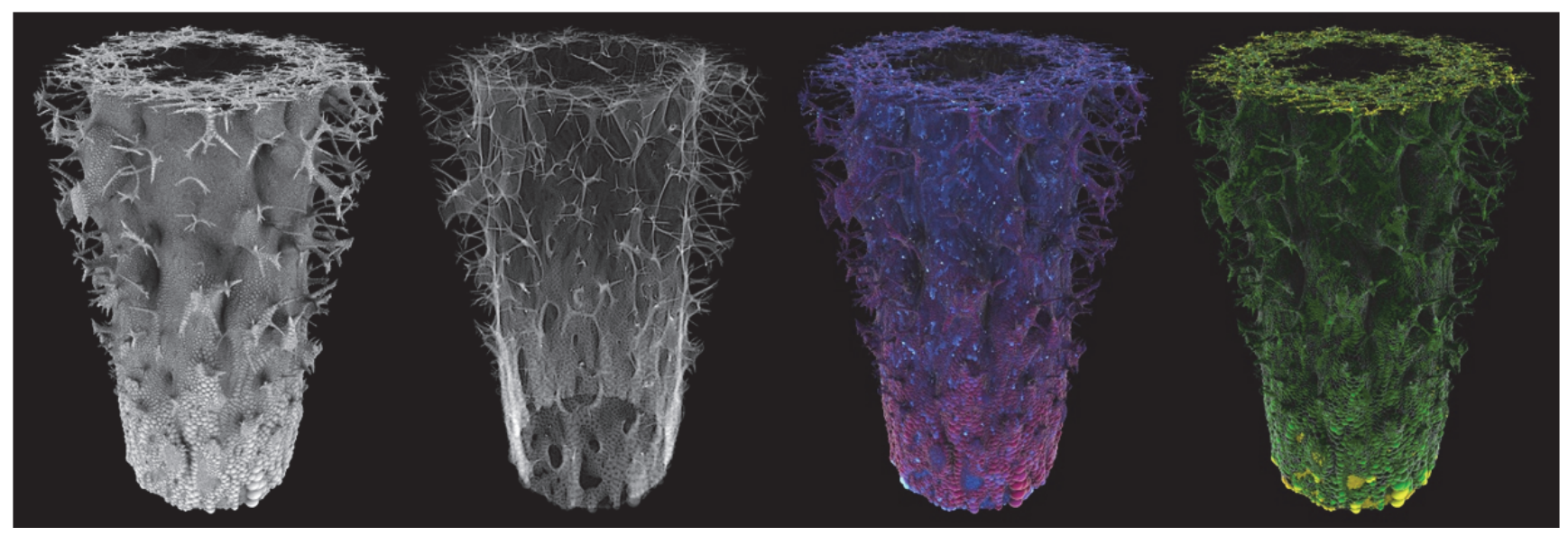

Figure 5: 'Four different renderings of Mutant Vase Form 1700070256 11012261' by Andy Lomas.
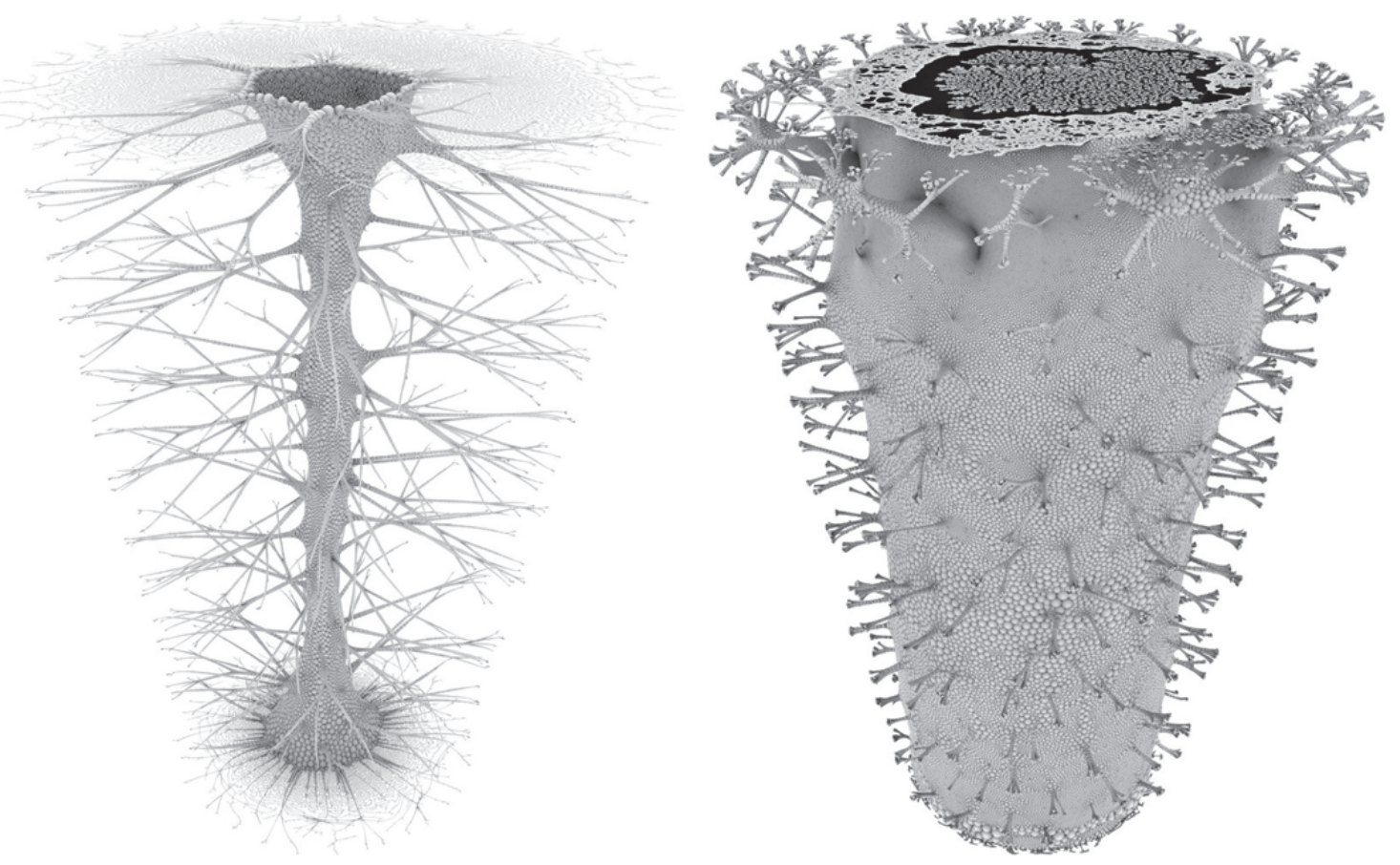

Figure 6: 'Two Mutant Vase Forms' by Andy Lomas.
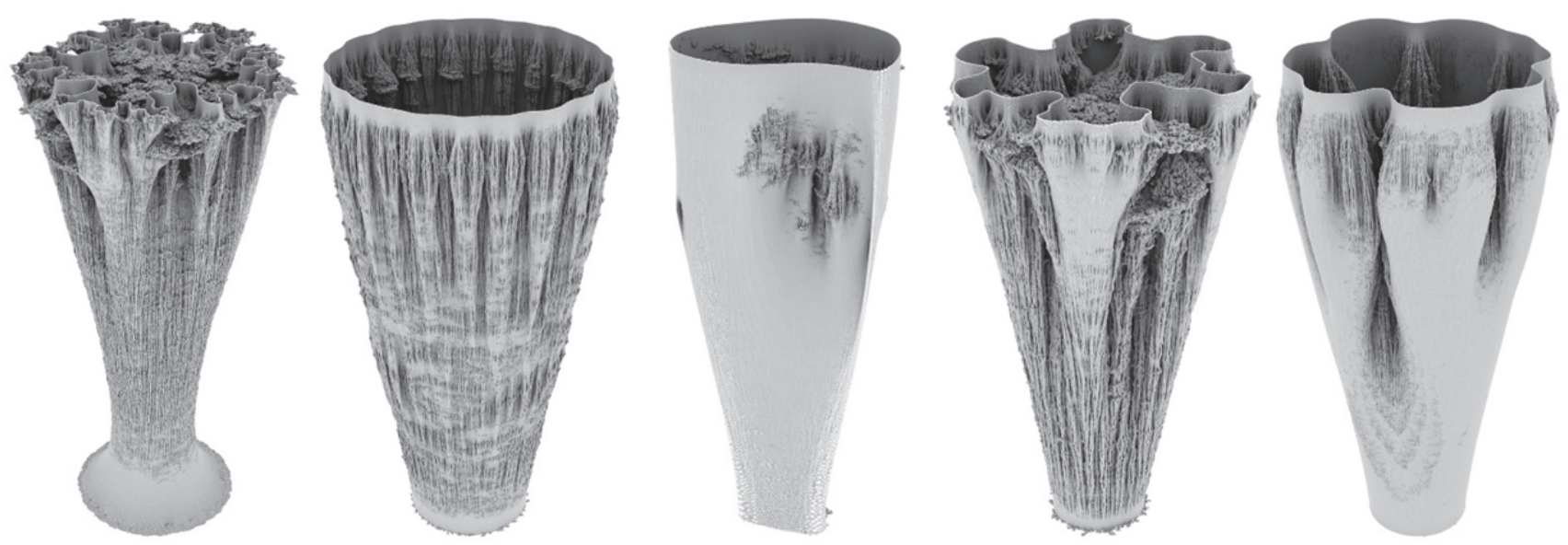

Figure 7: 'Five Vase Forms' by Andy Lomas. 
Biography

Andy Lomas is a digital artist, mathematician, Emmy award winning supervisor of computergenerated effects, and lecturer in Creative Computing at Goldsmiths University of London. Inspired by the work of Alan Turing, D'Arcy Thompson and Ernst Haeckel, his art work explores how complex sculptural forms can be created emergently by simulating growth processes.

He has exhibited internationally, including at the Centre Pompidou, V\&A, The Royal Society, Science Museum, SIGGRAPH, Japan Media Arts Festival, Ars Electronica Festival, Kinetica, Los Angeles Municipal Art Gallery, Centro Andaluz de Arte Contemporaneo, and the ZKM. His work is in the collections at the V\&A, the Computer Arts Society and the D'Arcy Thompson Art Fund Collection. In 2014 his work Cellular Forms won The Lumen Prize Gold Award.

His production credits include Walking with Dinosaurs, Matrix: Revolutions, Matrix: Reloaded, Over the Hedge, The Tale of Despereaux, and Avatar. He received Emmys for his work on The Odyssey (1997) and Alice in Wonderland (1999). Lomas has previously presented at EVA London Conferences (Lomas 2016; Bowen et al. 2018b).

\section{Judith Siefring, University of Oxford}

Title: Manuscripts and Archives, Maps and Music - Challenges of putting cultural heritage collections online

Since its foundation in 1602, the Bodleian Library has been dedicated to collecting and preserving artefacts of intellectual and cultural importance. Over the centuries, the library has amassed an enormous collection of print materials; in November 2015 it celebrated the acquisition of its 12 millionth printed item, a previously unseen copy of Percy Bysshe Shelley's Poetical Essay on the Existing State of Things (1811). Alongside its print collections, the Bodleian has acquired manuscripts, maps, music, photographs and other artworks, printed ephemera, and archival materials such as literary and political papers. Treasures of the library include the $16^{\text {th }}$-century chronicle of Aztec history known as the Codex Mendoza, fragments of the poems of ancient Greek poet Sappho, Shakespeare's First Folio, the medieval Gough Map, manuscript fragments of the Mishneh Torah (Repetition of the Law) by the greatest Jewish scholar of the Middle Ages Moses Maimonides, Mary Shelley's manuscript drafts of Frankenstein, Jane Austen's original draft of The Watsons, and a $9^{\text {th }}$-century manuscript of Euclid's mathematical work Stoicheia (Elements) with text in the original
Greek and additional manuscript annotations by its first owner.

Even this brief list of a handful of items from the Bodleian's collections illustrates their great variety and richness. However, this variety is both a joy and a challenge. The Bodleian greatly benefits from the vast knowledge and expertise of our specialist curators, but when it comes to making collections available online must rely on digital library specialists who are expert in the technologies required but not necessarily in all the various cultural traditions that have produced the artefacts with which they are working. Staff are often faced with tricky problems to solve as they try to make very disparate content available through a limited number of digital platforms. We explore some of the complexities that arise when putting cultural heritage collections online, with special reference to the Bodleian and other Oxford University collections. It suggests possible solutions or approaches to these challenges and stress the importance of open-source development communities, shared standards, collaboration and partnership.

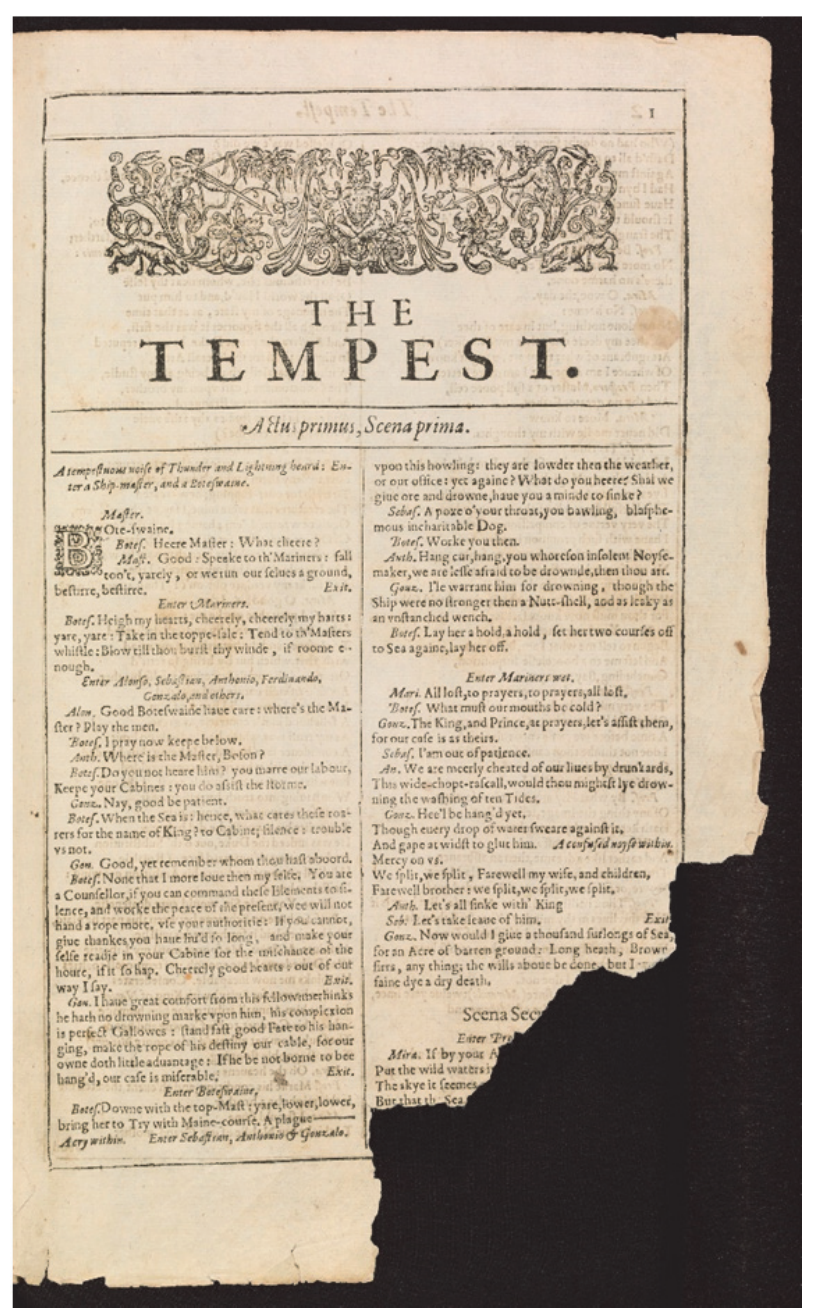

Figure 8: Page from Shakespeare's Tempest, image from The Bodleian First Folio: digital facsimile of the First Folio of Shakespeare's plays, Bodleian Arch. G c.7. (http://firstfolio.bodleian.ox.ac.uk). License: CC BY 3.0. 
Digital Art, Culture and Heritage: New constructs and consciousness Jonathan P. Bowen, Tula Giannini, Rachel Ara, Andy Lomas \& Judith Siefring

Biography

Judith Siefring is Head of Digital Research at the Bodleian Libraries, University of Oxford. She manages a programme of initiatives focused on creating digital tools and services to enable research and teaching, with a particular focus on making special collections content discoverable online. Resources developed and managed within Bodleian Digital Research include Digital Bodleian (https://digital.bodleian.ox.ac.uk), the Digital Manuscripts Toolkit (http://dmt.bodleian.ox.ac.uk), the William Henry Fox Talbot Catalogue Raisonné (http://talbot.bodleian.ox.ac.uk), and various TEI (Text Encoding Initiative) manuscript catalogues, including those for Georgian, Armenian, Tibetan, and Western medieval collections. Judith has a background in medieval studies, lexicography, book history, digital editing, and project management, and has a special interest in democratizing access to cultural heritage collections through digital development.

\section{CONCLUSION}

As computer power increases exponentially, some scientists predict that supercomputers with $\mathrm{Al}$ and machine learning, like 'Lucy in the Sky with Diamonds' (by the Beatles in 1967) and some scientists believe that we will be able to digitise the brain and upload it to the body (Elderkin 2018).

Others foresee that we will reach "Singularity" by 2045 as predicted by Ray Kurzweil (See Fig. 2), a so-called computer utopia (Kurzweil 2009), or will it be more like the dark-side of digital - or does it seem more likely that the increasing power of supercomputers, as the one being built by Intel which is "capable of a quintillion operations a second and will go online in 2021" (Gent 2019) will fuel an expanding digital universe of greater complexity and diversity, opening up new ways of thinking digitally and creatively, not sequential or linear, so that digital thinking gives way to complexity and non-hierarchical systems. But importantly, will computers make us smarter as we continue to integrate them into our mind and body as if becoming one with computational culture, expanding from smartphones, physical sensors and robotic interaction to more powerful devices yet to be designed.

The Symposium talks have been designed to cover a range of issues in digital theory and practice, in the context of art, culture, and heritage. A bibliography of related publications by the Symposium chairs and speakers is included below for further reading.
Online information concerning the EVA London 2019 Symposium is available under:

http://www.eva-london.org/eva-london2019/symposium/

Acknowledgements

The EVA London 2019 Symposium was supported as part of the EVA London 2019 Conference. Jonathan Bowen is grateful to Museophile Limited for financial support.

\section{REFERENCES}

Ara, R. and Giannini, T. (2017) The making of a digital (master)piece. In Bowen et al. (2017), pp 327-334. DOI: 10.14236/ewic/EVA2017.67

Ara, R. (2019) A conceptual artist programming for social change. In Giannini \& Bowen (eds.) (2019a), chapter 20.

Bellman, R. (1961) Adaptive Control Processes: A Guided Tour. Princeton: Princeton University Press.

Bowen, J. P., Diprose, G., and Lambert, N. (eds.) (2016) EVA London 2016: Electronic Visualisation and the Arts. BCS, Electronic Workshops in Computing. http://www.bcs.org/ewic/eva2016 (retrieved 9 May 2018).

Bowen, J. P., Diprose, G., and Lambert, N. (eds.) (2017) EVA London 2017: Electronic Visualisation and the Arts. BCS, Electronic Workshops in Computing. http://www.bcs.org/ewic/eva2017 (retrieved 9 May 2018)

Bowen, J. P. and Giannini, T. (2014) Digitalism: The new realism? In K. Ng, J. P. Bowen, and S. McDaid (eds.), EVA London 2014: Electronic Visualisation and the Arts. BCS, Electronic Workshops in Computing, pp. 324-331. DOI: $10.14236 /$ ewic/eva2014.38

Bowen, J. P. and Giannini, T. (2016) From analogue to digital in literature and art. In Bowen et al. (2016), pp. 14. DOI: $10.14236 /$ ewic/EVA2016.1

Bowen, J. P. and Giannini, T. (2019) The digital future for museums. In Giannini \& Bowen (eds.) (2019a), chapter 28.

Bowen, J. P., Giannini, T., and Polmeer, G. (2017) Coded communication: Digital senses and aesthetics, merging art and life. In Bowen et al. (2017), pp. 1-8. DOI: $10.14236 /$ ewic/EVA2017.1

Bowen, J. P., Giannini, T., Polmeer, G., Gannis, C., Gardiner, J., Kearney, J., Wands, B., and Weinel, J. (2018a) States of Begin: Art and identity in digital space and time. In Bowen et al. (2018c), pp. 1-7. DOI: 10.14236/ewic/EVA2018.1

Bowen, J. P., Trickett, T., Green, J. B. A., and Lomas, A. (2018b) Turing's genius - defining an apt microcosm. In Bowen et al. (2018c), pp. 155-162. DOI: 10.14236/ewic/EVA2018.31

Bowen, J. P., Weinel, J., Diprose, G., and Lambert, N. (eds.) (2018) EVA London 2018: Electronic Visualisation and the Arts. BCS, Electronic Workshops in Computing. http://www.bcs.org/ewic/eva2018 (retrieved 22 March 2019) 
British Library (2018) Living with Machines. The Alan Turing Institute and the British Library awarded £9.2 million for a major new project set to revolutionise research. British Library, 19 December 2018. https://www.bl.uk/press-releases/2018/december/livingwith-machines (retrieved 27 March 2019).

Christie's (2018) Is artificial intelligence set to become art's next medium? Christies, 12 December 2018. https://www.christies.com/features/A-collaborationbetween-two-artists-one-human-one-a-machine-93321.aspx (retrieved 27 March 2019).

Chun, R. (2017) It's Getting Hard to Tell If a Painting Was Made by a Computer or a Human. Artsy, 21 Sepember 2017. https://www.artsy.net/article/artsyeditorial-hard-painting-made-computer-human (retrieved 27 March 2019).

Contreras-Koterbay, S. and Mirocha, $七$. (2016) The New Aesthetic and Art: Constellations of the postdigital. Institute of Network Cultures, Amsterdam, p.245. http://networkcultures.org/wp-

content/uploads/2016/07/TOD20-final.pdf (retrieved 27 March 2019)

Donoho, D. L. (2000) High-Dimensional Data Analysis: The Curses and Blessings of Dimensionality. Presented at AMS Math Challenges Lecture, Los Angeles, CA, USA, 6-11 August 2000.

Elderkin, B. (2018) Will We Ever Be Able to Upload a Mind to a New Body? Gozmodo, 2 May 2018. https://gizmodo.com/will-we-ever-be-able-to-upload-amind-to-a-new-body-1822622161 (retrieved 27 March 2019).

FIT Newsroom. (2019) Exhibition: The Future is Immersive. https://news. fitnyc.edu/event/exhibition-thefuture-is-immersive-closes/ (retrieved 7 April 2019).

Galeon, D. (2017) Our Computers Are Learning How to Code Themselves - Human coders beware. Futurism, 24 February 2017. https://futurism.com/4-our-computersare-learning-how-to-code-themselves (retrieved 27 March 2019).

Gent, E. (2019) Intel Is Building the World's Most Powerful Supercomputer. Singularity Hub, 25 March 2019. https://singularityhub.com/2019/03/25/intel-isbuilding-the-worlds-most-powerful-supercomputer/ (retrieved 27 March 2019).

Giannini, T. and Bowen, J. P. (2016) Curating digital life and culture: Art and information. In Bowen et al. (2016), pp. 237-244.

DOI: 10.14236/ewic/EVA2016.46

Giannini, T. and Bowen, J. P. (2017) Life in code and digits: When Shannon met Turing. In Bowen et al. (2017), pp. 51-58. DOI: 10.14236/ewic/EVA2017.9

Giannini, T. and Bowen, J. P. (2018) Of museums and digital culture: A landscape view. In Bowen et al. (2018), pp. 172-179.

DOI: $10.14236 /$ ewic/EVA2018.34
Giannini, T. and Bowen, J. P. (eds.) (2019a) Museums and Digital Culture: New Perspectives and Research. Springer, Series on Cultural Computing.

Giannini, T. and Bowen, J. P. (2019b) Art and Activism at museums in a post-digital world. In Weinel et al. (2019). (This volume.)

Hayles, N. K. (2007) Intermediation: The Pursuit of a Vision. New Literary History, 38(1), pp. 99-125, Winter 2007. Johns Hopkins University Press. DOI: 10.1353/nlh.2007.0021

Han, H. (2019) Virtual World Construction and the Relationship to Creativity in Art Education. Canadian Review of Art Education, 46(1), pp. 85-100, 2019. https://www.academia.edu/38285794 (retrieved 27 March 2019).

Kauffman, S. (1996). At Home in the Universe: The Search for Laws of Self-organization and Complexity. London: Penguin.

Kurzweil, R. (2009) The Coming Singularity. Big Think. YouTube, 28 April 2009.

https://www.youtube.com/watch?v=1ulzS1uCOcE (retrieved 27 March 2019).

Lomas, A. (2005) Aggregation: Complexity out of simplicity. In ACM SIGGRAPH 2005 Sketches. New York: ACM. DOI: 10.1145/1187112.1187230

Lomas, A. (2007) Flow. Morphogenetic Creations. http://www.andylomas.com/flow.html (retrieved 27 March 2019).

Lomas, A. (2016) Species Explorer: An interface for artistic exploration of multi-dimensional parameter spaces. In Bowen et al. (2016), pp. 95-102. DOI: 10.14236/ewic/EVA2016.23

Lomas, A. (2018). On Hybrid Creativity. Arts 2018, 7(3), p. 25. DOI: $10.3390 /$ arts7030025

Lomas, A. (2019) Morphogenetic Creations: Exhibiting and collecting digital art. In Giannini \& Bowen (eds.) (2019a), chapter 17.

McDougall, A. C. (2019) What is Cyber-Consciousness? Digital Intermediation between Consciousness and Computer through Postmodern Tension in Tao Lin's Taipei. C21 Literature: Journal of 21st-century Writings, 7(1), pp. 1-27, January 2019. DOI: 10.16995/c21.555

Papadimitriou, I., Addis, J., Lomas, A., Dekker, L., Singporewala, K., and Tresset, P. (2017) Digital Futures: Lumen Big Reveal. In Bowen et al. (2017), pp. 438-440. DOI: 10.14236/ewic/EVA2017.86

Polmeer, G. (2016) Sublating time: Hegel's speculative philosophy and digital aesthetics. In Bowen et al. (2016), pp. 257-264. DOI: 10.14236/ewic/EVA2016.49

Siefring, J. (2019) Democratizing discovery: The impact of digital culture on the research library. In Giannini \& Bowen (eds.) (2019a), chapter 25

Weinel, J., Bowen, J. P., Diprose, G., and Lambert, N. (eds.) (2019) EVA London 2019: Electronic Visualisation and the Arts. BCS, Electronic Workshops in Computing. (This volume.) http://www.bcs.org/ewic/eva2019 